\title{
Analysis of energy storage system with distributed hydrogen production and gas turbine
}

\author{
JANUSZ KOTOWICZ \\ EUKASZ BARTELA \\ KLAUDIA DUBIEL-JURGAŚ ${ }^{*}$
}

Silesian University of Technology, Institute of Power Engineering and Turbomachinery Konarskiego 18, 44-100 Gliwice, Poland

\begin{abstract}
Paper presents the concept of energy storage system based on power-to-gas-to-power (P2G2P) technology. The system consists of a gas turbine co-firing hydrogen, which is supplied from a distributed electrolysis installations, powered by the wind farms located a short distance from the potential construction site of the gas turbine. In the paper the location of this type of investment was selected. As part of the analyses, the area of wind farms covered by the storage system and the share of the electricity production which is subjected storage has been changed. The dependence of the changed quantities on the potential of the hydrogen production and the operating time of the gas turbine was analyzed. Additionally, preliminary economic analyses of the proposed energy storage system were carried out.
\end{abstract}

Keywords: Power-to-Gas-to-Power; Hydrogen; Gas turbine; Electrolysis

\section{Introduction}

The increase in the share of renewable energy sources, observed in recent years, which are characterized by variable in time production potential, contributes to the intensification of research into energy storage systems. This is primarily due to the variability of electricity production by solar and wind power plants. At present in Poland, the installed power in wind power plants amounts to $5813 \mathrm{MW}$ [1], whereas in power plants generating

${ }^{*}$ Corresponding Author. Email: klaudia.dubiel-jurgas@polsl.pl 
electricity from solar radiation it is $100 \mathrm{MW}$. For comparison, in 2011 it was $1616 \mathrm{MW}$ and $1.1 \mathrm{MW}$, respectively [1]. Thus, within 5 years, more than 3 times increase in installed power in wind power and almost 90 times in solar power was recorded. The increase in the share of this type of source in the power system increases the disproportion between production and consumption of electricity by final consumers. One way of storing energy and thus bridging the gap between electricity demand and electricity supply, analyzed in this paper, is hydrogen production in the electrolysis process, using excess electricity (power-to-gas). Then, hydrogen can be directly used for energy purposes during periods of increased demand for electricity in the system, e.g., in gas piston engines, gas turbines, fuel cells, or as a substrate for chemical reactions such as methanisation.

\section{Description of the energy storage system with selection of the location of gas turbine}

The article presents a concept of energy storage system using a gas turbine (GT) co-firing hydrogen with natural gas. Hydrogen, which is a product of electrolysis of water, is produced in several separate electrolysis installations (EI), each of which cooperates with a single wind farm. Distributed sources of hydrogen production are located in a short distance from the proposed construction site of the gas turbine. The transport of hydrogen is carried out by tube trailers, each with a capacity of $20 \mathrm{~m}^{3}$, at a pressure of $20 \mathrm{MPa}$. Analyses were conducted for a specific investment location. The main criteria for selecting locations for this type of investment are: the significant installed power of nearby wind farms and the availability of the power grid and gas network, due to the proper functioning of the gas turbine. A schematic diagram of the system was presented in Fig. 1.

The intensity and force of the wind are highly relevant to the planning of wind farms. The Institute of Meteorology and Water Management draws wind maps with the division into 5 zones of the wind energy, from the most favourable to the least favourable conditions for the construction of a wind power plant [3]. In Poland, the most favourable conditions (zone I) have the Baltic coastline, the area of the Gulf of Gdansk and the Suwalszczyzna region. The windiness is often dependent on local conditions, so investments are preceded by a few years of measurements at the site of the planned wind farm. In Poland, the highest density of large wind farms (>5 MW) is observed in the Slupsk and Koszalin regions, as illustrated in Fig. 2. Within 


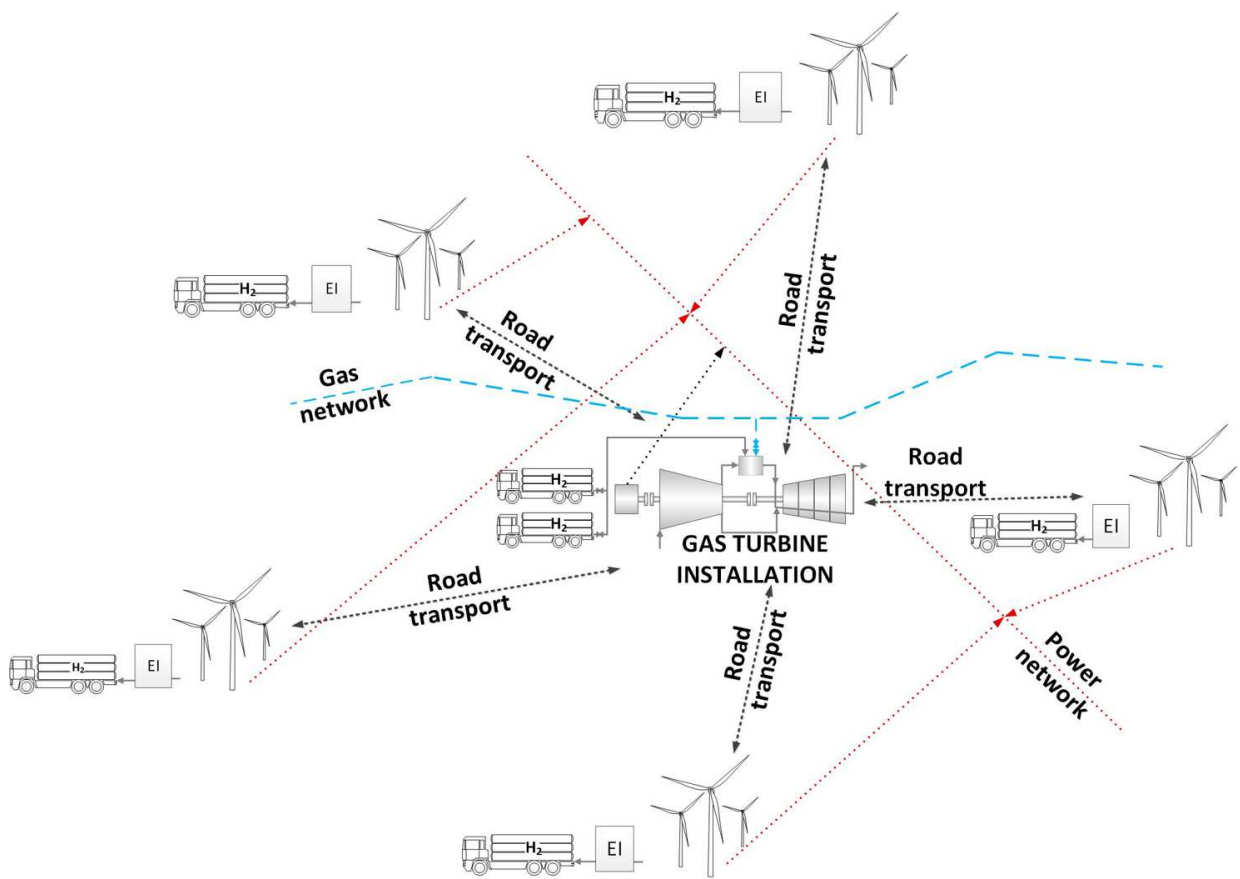

Figure 1: Scheme of energy storage system with gas turbine and distributed hydrogen production.

the analyses, the location of the installation of gas turbine between the towns of Tychowo and Noskowo in the Western Pomeranian voivodship in the Slawno district was selected. This location is justified because of a short road distance not exceeding $40 \mathrm{~km}$ from at least 19 wind farms, each with installed power of at least $5 \mathrm{MW}$. The total installed power of the analyzed 19 wind farms is $623.9 \mathrm{MW}$. In the discussed concept of the system, these farms are also the places of hydrogen generation. In addition, within close proximity there is the existing natural gas transmission pipeline, which is the nominal GT fuel, and the $110 \mathrm{kV}$ power transmission line, allowing evacuation of power from GT.

The location of large wind farms (> $5 \mathrm{MW})$ in Poland with the marked analyzed area are presented in Fig. 2. Details are shown in Fig. 3. 


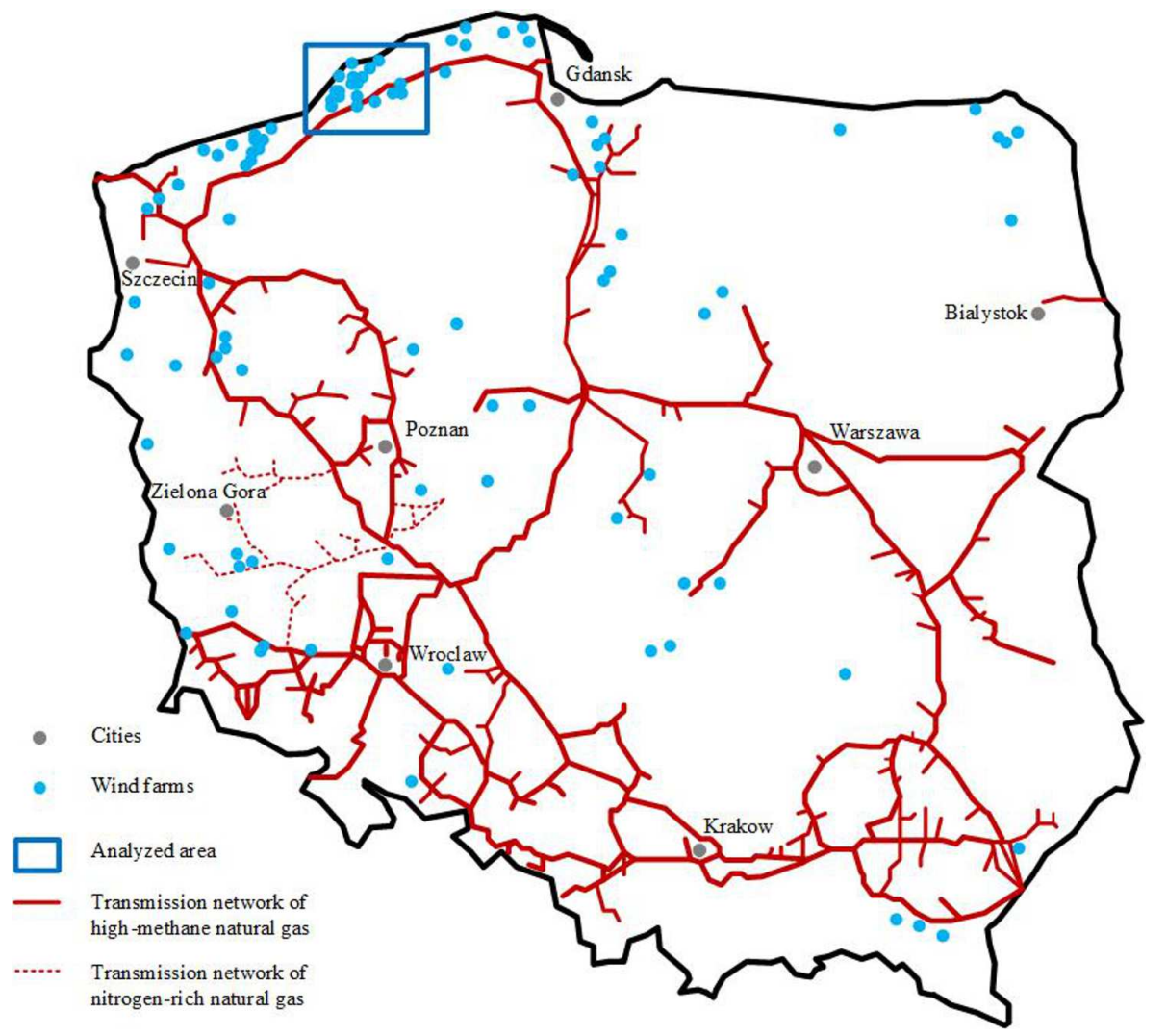

Figure 2: The location of wind farms with installed power over $5 \mathrm{MW}$, with the natural gas transmission network.

\section{Methodology and assumptions}

The input data, required for system analyses, were the hourly characteristics of power for the annual operating cycle of the wind farms. The analyses used one wind farm power characteristic, scaled depending on the installed power of individual farms. An example basic power characteristic for $100 \mathrm{MW}$ installed power wind farm is shown in Fig. 4.

The influence of the distance of the wind farms included in the storage system to the gas turbine on the hydrogen production potential was also analyzed. Details of the installed power of individual wind farms and the road distances between the planned plant and farms are shown in Tab. 1. 


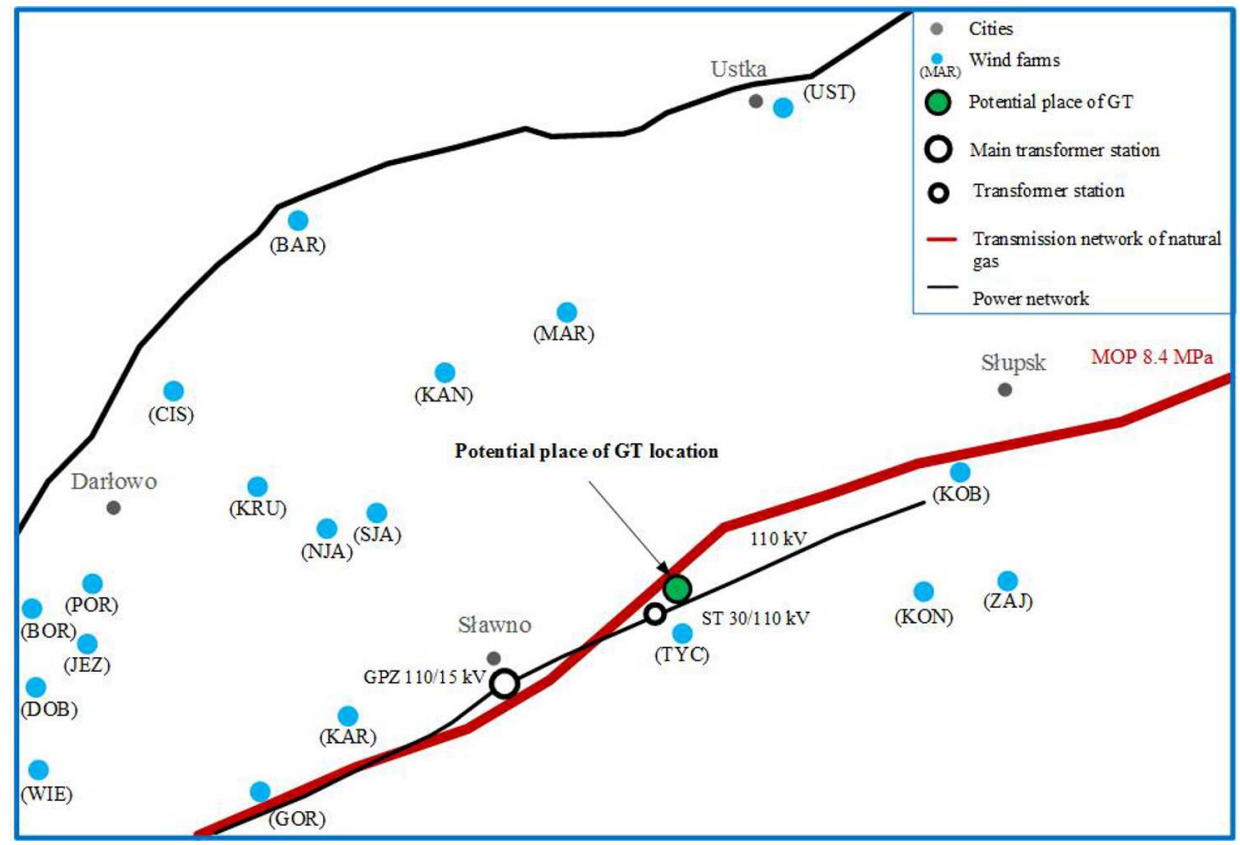

Figure 3: Analyzed area with the marked wind farms, natural gas transmission network and high voltage power grid.

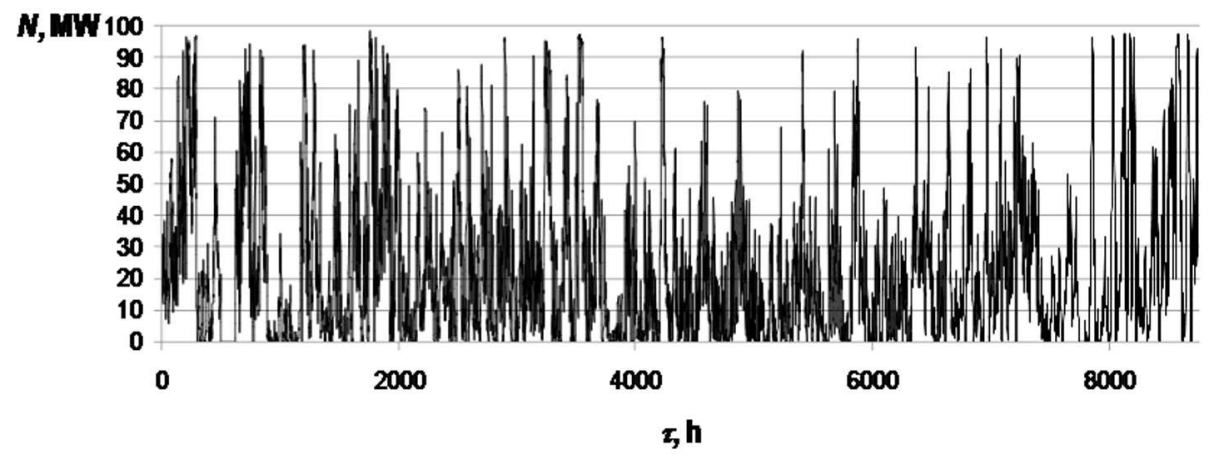

Figure 4: An example of power characteristics of wind farm with installed power of $100 \mathrm{MW}$ for the annual operating cycle.

As the road distance to the GT increases, the installed power of wind farms, included in the storage system is increasing. The analyses considered the variants included in Tab. 2. 
Table 1: The installed power of the analyzed wind farms and the road distance to the GT installation.

\begin{tabular}{|c|c|c|c|}
\hline No. & Wind farm & Installed power, MW & Road distance to the $\mathrm{GT}, \mathrm{km}$ \\
\hline 1 & BAR & 22.5 & 29 \\
\hline 2 & BOR & 32.5 & 35 \\
\hline 3 & CIS & 20.0 & 38 \\
\hline 4 & $\mathrm{DOB}$ & 27.5 & 36 \\
\hline 5 & GOR & 37.5 & 25 \\
\hline 6 & JEZ & 27.5 & 35 \\
\hline 7 & $\mathrm{KAN}$ & 20.0 & 25 \\
\hline 8 & KAR & 40.0 & 19 \\
\hline 9 & $\mathrm{KOB}$ & 41.4 & 20 \\
\hline 10 & $\mathrm{KON}$ & 42.0 & 23 \\
\hline 11 & KRU & 17.5 & 24 \\
\hline 12 & MAR & 80.0 & 24 \\
\hline 13 & NJA & 25.0 & 22 \\
\hline 14 & POR & 24.0 & 38 \\
\hline 15 & SJA & 22.5 & 20 \\
\hline 16 & TYC & 50.0 & 1 \\
\hline 17 & UST & 21.0 & 37 \\
\hline 18 & WIE & 25.0 & 35 \\
\hline 19 & ZAJ & 48.0 & 21 \\
\hline
\end{tabular}

An assumption has been made that the particular installations of electrolysis operate in daily cycle and are supplied by electricity from a wind farm cooperating with it in the period of low demand (night valley), i.e., between $10 \mathrm{pm}$ and $6 \mathrm{am}$. It was assumed that the efficiency of installation is equal to $67 \%$. This quantity is defined as

$$
\eta_{E I}=\frac{\dot{m}_{\mathrm{H} 2} \mathrm{HHV}}{N_{\mathrm{EI}}}
$$

where: $\dot{m}_{\mathrm{H} 2}$ - stream of produced hydrogen, HHV - Higher Heating Value, $N_{\mathrm{EI}}$ - electrical power supply of electrolysis installation.

A decisive factor for the amount of electricity to be stored is the socalled degree of storage, $\gamma_{s}$, defined as the ratio of the amount of electricity directed to electrolysis process, $E_{\text {el_EI }}$, to the total amount of electricity 
Energy storage system with hydrogen production...

Table 2: List of analyzed scenarios of a distributed storage system.

\begin{tabular}{|c|c|c|}
\hline Variant & $\begin{array}{l}\text { The total installed power of wind } \\
\text { farms covered by the system, MW }\end{array}$ & $\begin{array}{c}\text { Road distance } \\
\text { to the GT, km }\end{array}$ \\
\hline A & 50 & 1 \\
\hline B & 90 & 19 \\
\hline C & 153.9 & 20 \\
\hline D & 201.9 & 21 \\
\hline E & 226.9 & 22 \\
\hline F & 268.9 & 23 \\
\hline G & 366.4 & 24 \\
\hline H & 423.9 & 25 \\
\hline I & 446.4 & 29 \\
\hline J & 531.4 & 35 \\
\hline K & 558.9 & 36 \\
\hline L & 579.9 & 37 \\
\hline M & 623.9 & 38 \\
\hline
\end{tabular}

generated by wind farm during the year, $E_{e l} \quad$ a $[4]$ :

$$
\gamma_{\mathrm{s}}=\frac{E_{\text {el_EI }}}{E_{\text {el_a }}} .
$$

The power supply of the electrolysis installation is limited by its nominal power determined at assumed value of $\gamma_{s}$ or by instantaneous potential of the wind farm. In the period of low demand, the part of wind farm's power that does not supply the electrolysis installation is directed to the power grid. In the situation of low potential of wind farms, electrolysis installations operate with power supply lower than nominal.

An example of the daily characteristic of the installation operation with assumed the power characteristic of wind farm shown in Fig. 4 and $\gamma_{s}=0.2$ was presented in Fig. 5. In order to obtain the assumed degree of storage, the required nominal power of the electrolysis installation cooperating with such a farm is $22.7 \mathrm{MW}$. In addition, in Fig. 5 the night valley period and the production of a wind farm directed at that time to the electrolysis installation were marked.

The surplus of electricity, occurring in the periods of night valleys and the production outside the night valleys which are directed to the power grid were also marked. 


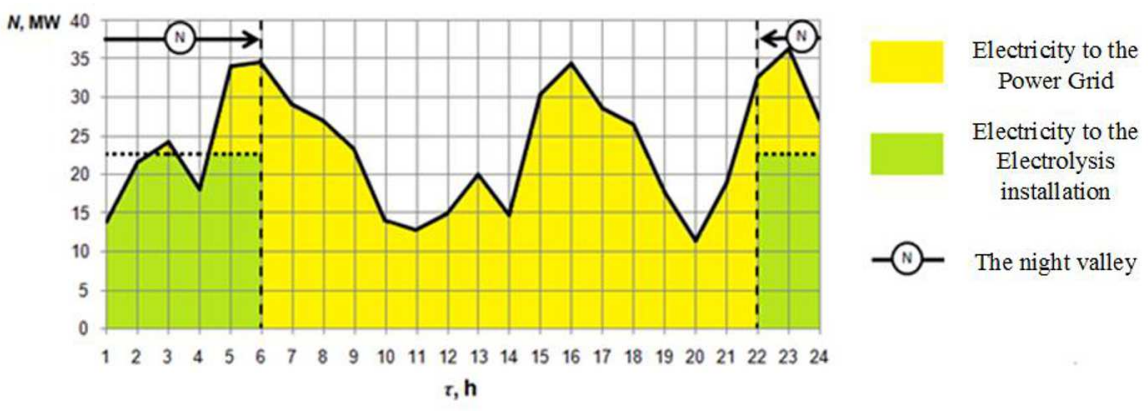

Figure 5: Randomly selected power characteristics of wind farm with installed power of $100 \mathrm{MW}$ for daily operation cycle, with assumed degree of storage of 0.2 and determined nominal power of electrolysis installation (22.7 MW).

\section{Gas turbine}

It was assumed that the gas turbine, which is to be applied in the system, it is the GE LMS100 construction. The basic data of the turbine are summarized in Tab. 3.

To perform analyses, the own computational code which allows to simulate the change in operating parameters of a gas turbine unit in the case of load changes, ambient conditions and supply gas parameters other than those specified in the nominal operating point of the analyzed unit, were used [2]. The computation code of the gas turbine, which is presented in details in [2], allows simulations of gas turbines of various configurations, including units with inter-stage cooling of compressed air, as occurs in the analyzed GE LMS100PB gas turbine. A diagram of the gas turbine with marked characteristic points is presented in Fig. 6.

An important issue in the case of performing analyses for the commercially available turbines is to develop assumptions for calculations that will allow for the most accurate representation of the structural features of the unit. The model validation for nominal operating conditions of the gas turbine was made. For this purpose, the data, which are made available by manufacturers and literature [5-8] were used. In this case, the power of the gas turbine, the electrical efficiency, the compression ratio, the flue gas temperature behind the combustion chamber and the temperature of flue gas leaving the expander, are known. The basic input quantities in the computational algorithm are the compression ratio and the flue gas temperature behind the combustion chamber. Other sizes, among those 
Table 3: Characteristic quantities for LMS100PB turbine.

\begin{tabular}{|c|c|c|c|c|}
\hline Component & Characteristic quantity & Turbine model & GE LMS100PB & Unit \\
\hline \multirow[t]{4}{*}{ Inlet } & Ambient temperature & 15 & 15 & ${ }^{\circ} \mathrm{C}$ \\
\hline & Ambient pressure & 101.325 & 101.325 & $\mathrm{kPa}$ \\
\hline & Relative humidity & 60 & 60 & $\%$ \\
\hline & Pressure drop & 1.0 & $\mathrm{NA}$ & $\%$ \\
\hline \multirow[t]{8}{*}{ Compressors } & Total compression ratio & 42 & 42 & - \\
\hline & Air flow & 225,4 & $\mathrm{NA}$ & $\mathrm{kg} / \mathrm{s}$ \\
\hline & $\begin{array}{l}\text { Pressure behind low- } \\
\text { pressure compressor }\end{array}$ & 390 & 390 & $\mathrm{kPa}$ \\
\hline & $\begin{array}{l}\text { Pressure behind inter } \\
\text { stages cooler }\end{array}$ & 380 & 380 & $\mathrm{kPa}$ \\
\hline & Temperature behind cooler & 35 & 35 & ${ }^{\circ} \mathrm{C}$ \\
\hline & Isentropic efficiency C (L) & 88.0 & $\mathrm{NA}$ & $\%$ \\
\hline & Isentropic efficiency $\mathrm{C}(\mathrm{H})$ & 88.0 & NA & $\%$ \\
\hline & Mechanical efficiency & 99.5 & NA & $\%$ \\
\hline \multirow[t]{4}{*}{ Combustion } & Fuel & Natural gas & Natural gas & \\
\hline & LHV (lower heating value) & 50.0 & NA & $\mathrm{MJ} / \mathrm{kg}$ \\
\hline & Stream of fuel & 4.92 & NA & $\mathrm{kg} / \mathrm{s}$ \\
\hline & Pressure drop & 4.4 & NA & $\%$ \\
\hline \multirow[t]{8}{*}{ Turbine } & $\begin{array}{l}\text { Outlet temperature of flue } \\
\text { gas }\end{array}$ & 1380 & 1380 & ${ }^{\circ} \mathrm{C}$ \\
\hline & $\begin{array}{l}\text { Outlet temperature of flue } \\
\text { gas }\end{array}$ & 420.8 & 421.0 & ${ }^{\circ} \mathrm{C}$ \\
\hline & $\begin{array}{lll}\begin{array}{l}\text { Isentropic efficiency of } \\
\text { stage }\end{array} & \\
\end{array}$ & 89.0 & $\mathrm{NA}$ & $\%$ \\
\hline & $\begin{array}{l}\text { Ratio of amount of cooling } \\
\text { air }\end{array}$ & 17.5 & $\mathrm{NA}$ & $\%$ \\
\hline & $\begin{array}{l}\text { Cooling air distribution in- } \\
\text { dicator }\end{array}$ & $50 / 35 / 15 / 0$ & NA & $\%$ \\
\hline & Outlet pressure of turbine & 102.5 & NA & $\mathrm{kPa}$ \\
\hline & Stream of flue gas & 230.3 & NA & $\mathrm{kg} / \mathrm{s}$ \\
\hline & Mechanical efficiency & 99.0 & NA & $\%$ \\
\hline Generator & Efficiency & 98.5 & NA & $\%$ \\
\hline \multirow[t]{2}{*}{ General } & Power & 108.0 & 108,0 & MW \\
\hline & $\begin{array}{l}\text { Efficiency of electricity } \\
\text { generation }\end{array}$ & 43.92 & 43,90 & $\%$ \\
\hline
\end{tabular}


mentioned above, are obtained as the results of calculations and are used for selection of other input quantities, which are present in the algorithm. The quantities taken from the literature, remaining assumptions and results from the calculations of the developed LMS100PB turbine model are presented in Tab. 3. As a nominal fuel, natural gas with $100 \% \mathrm{CH}_{4}$ was assumed.

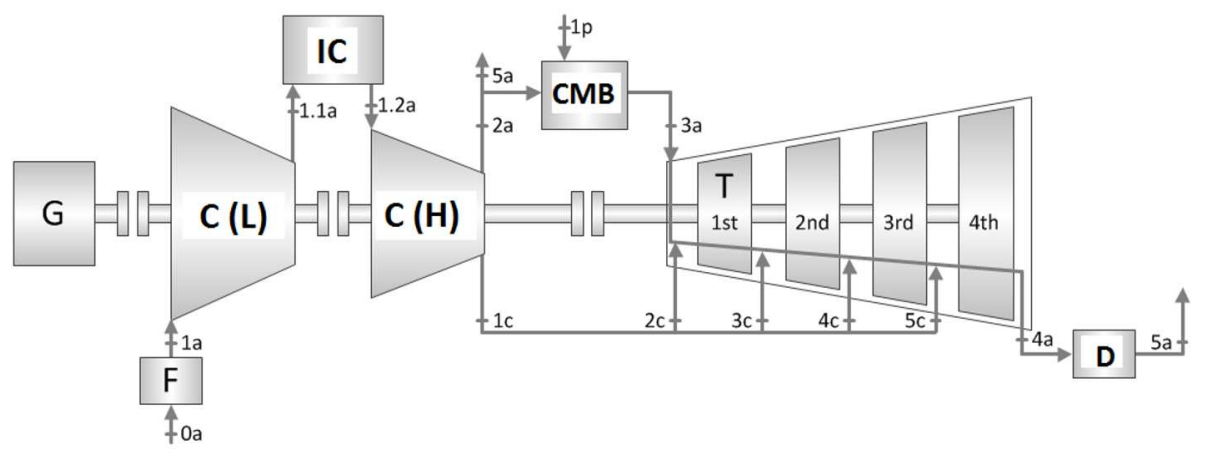

Figure 6: Diagram of gas turbine, where $\mathrm{F}$ - air filter, $\mathrm{S}$ - compressors $(\mathrm{C}(\mathrm{L})$ - low pressure section, $\mathrm{C}(\mathrm{H})$ - high pressure section), IC - inter stages cooler, CMB - combustion chamber, $\mathrm{T}$ - expander of turbine, $\mathrm{G}$ - electricity generator, $\mathrm{D}$ - dampler, a-air/exhaust, c - cooling air, $\mathrm{p}$ - fuel.

It was assumed that the gas turbine operates in a daily cycle, during the period of peak demand for electricity. In each case, a fuel is a mixture of hydrogen and natural gas, taken from the transmission network. During the analyses, the hydrogen volume content of the mixture was changed between $20 \%$ and $70 \%$. The nominal power of the gas turbine (with natural gas) is $108 \mathrm{MW}$. In the framework of the present analyses, the impact of hydrogen content in the mixture with natural gas was also examined taking into account basic quantities of the gas turbine: efficiency and power. The characteristics of the effects of hydrogen volume fraction in the mixture with natural gas, on the efficiency of the gas turbine and its power is presented in Fig. 7.

\section{Analyses results}

The production potential of hydrogen depends on the total power of wind farms covered by the energy storage system, which for the indicated location is determined by the maximum distance determining the activity area, the 


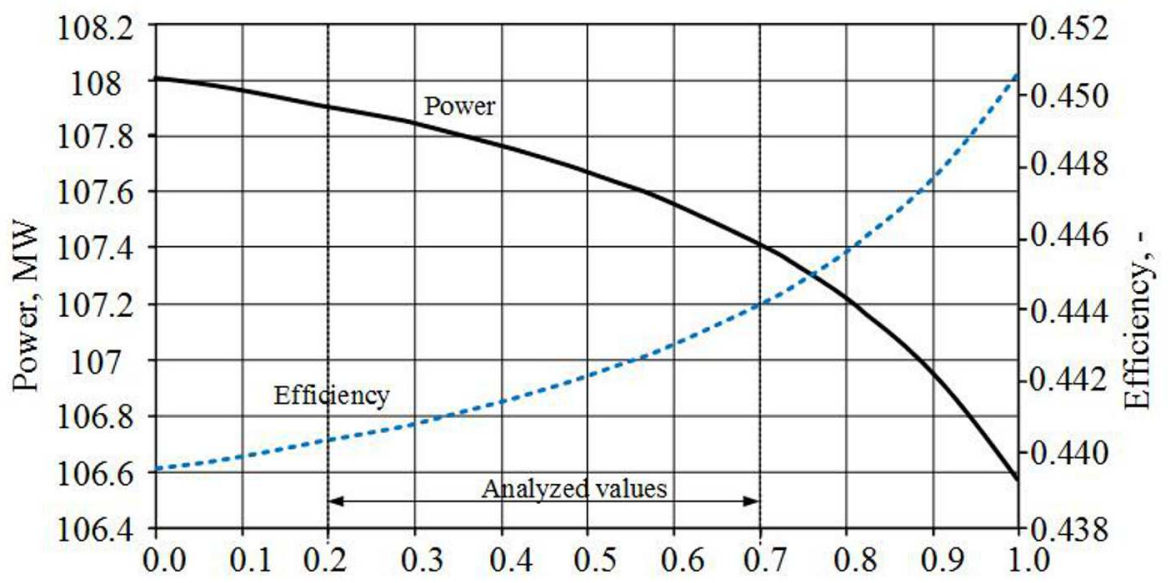

Volume fraction of $\mathrm{H}_{2}$, -

Figure 7: Power and efficiency of the gas turbine, as a function of the volume fraction of hydrogen in the gas mixture.

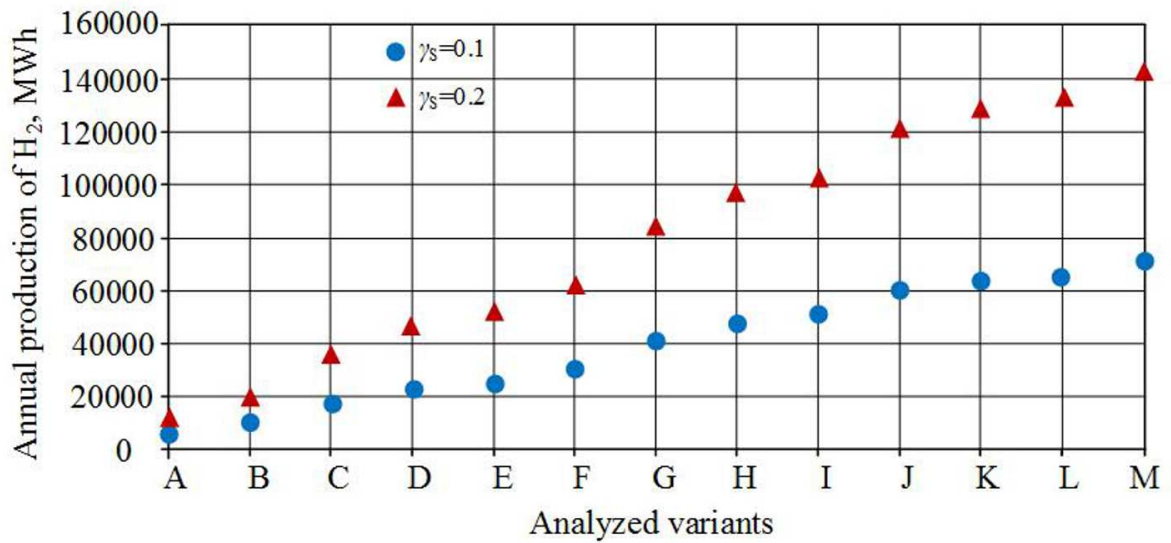

Figure 8: The amount of hydrogen produced in the year for the analyzed variants in case of two values of the degree of storage.

wind farm's production potential and the selected value of the degree of storage. The amount of produced hydrogen per year for different variants, differentiated by installed power of the wind farms is shown in Fig. 8. The presented results were obtained for two values of the degree of storage: 0.1 and 0.2 . 
In the case of the energy storage system, that is the subject of this analyses, the loading and unloading of the storage take place within the daily operation cycle. It should be noted that the GE LMS100 turbine is characterized by favourable start-up characteristics, mainly a short startup time of approximately $10 \mathrm{~min}$, from a cold condition. In the case of a gas turbine designed to work as a peak source of energy, the start-up time is important - the lower is operation time of the gas turbine, the more important it is. This is mainly due to relatively high fuel consumption in relation to electricity production. The start-up characteristics, showing the relative change in electrical power and relative change in the chemical energy flux of fuel (referenced to the nominal values), which was assumed for starting the turbine are shown in Fig. 9.

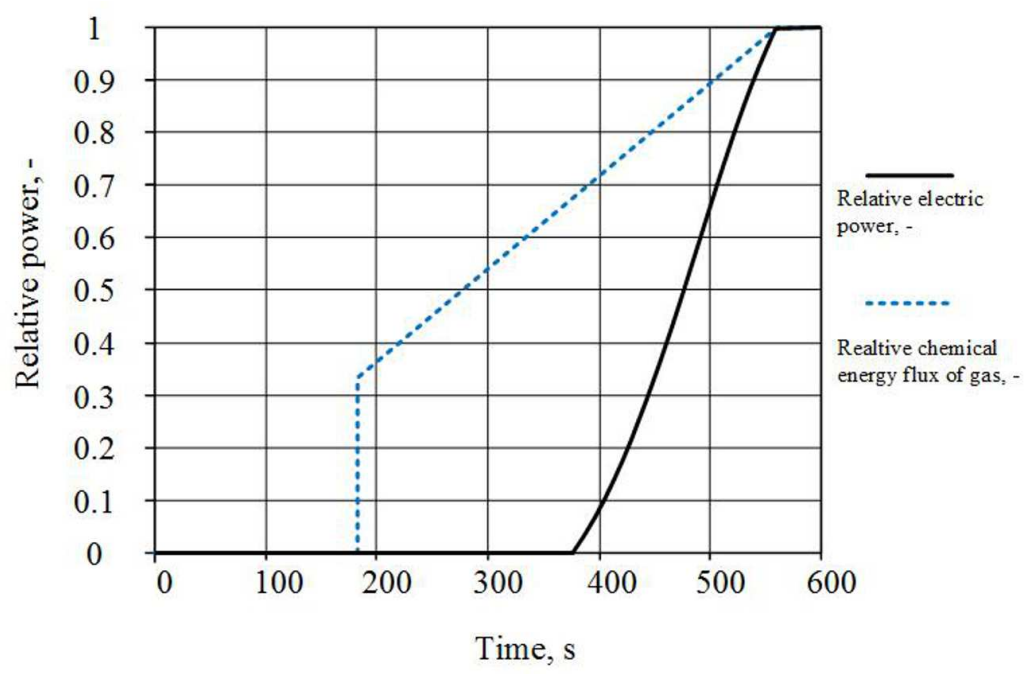

Figure 9: Relative electrical power and chemical energy flux during start-up of the analyzed turbine.

With the natural gas supply, the average efficiency of the GE LMS100 gas turbine at its start-up is only $19.07 \%$. For the first hour of operation of this turbine, the average efficiency is $41.69 \%$, which represented less than $95 \%$ of the nominal efficiency (43.9\%). The start-up period, due to low efficiency, will affect the average efficiency of the turbine during its daily operation. The shorter operation time, the stronger impact of start-up period. The characteristics of the average efficiency, relative to nominal efficiency, as a function of operating time of gas turbine are shown in Fig. 10. 


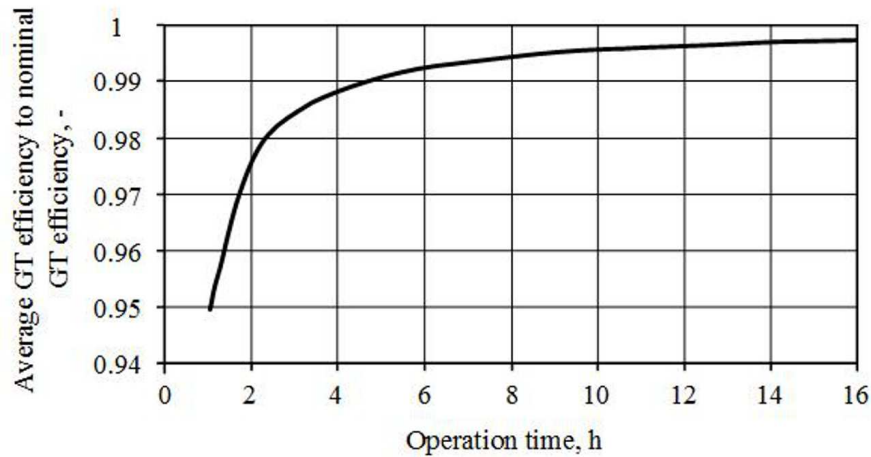

Figure 10: Average efficiency of gas turbine, relative to nominal efficiency, as a function of operating time.

As part of the analysis, the road distance from the gas turbine and thus the total installed power of the wind farms covered by the storage system, was changed. As shown in Fig. 8, the higher the distance, the greater the amount of stored hydrogen. The analyses were carried out for two different values of the degree of storage: 0.1 and 0.2 . The maximum operation times of the gas turbine that would be required in the daily cycle of its operation for the energy use of the maximum amount of stored hydrogen with $\gamma_{s}=0.1$ were presented in Fig. 11. Results for $\gamma_{s}=0.2$ were summarised in Fig. 12. The work of the gas turbine for the analyzed energy storage system, should be planned in the period of peak daily demand for electricity. Such a period in the national power system occurs generally between hours 12 am and $8 \mathrm{pm}$. Assuming that the operating time of gas turbine in the daily cycle would be 8 hours, it could be seen that many of the analyzed options would not allow to use the total amount of stored hydrogen. For the degree of storage 0.1 , this relates to selected cases, where the hydrogen content of the fuel mixture would be $20 \%$ and $30 \%$. Accordingly, for a hydrogen fraction of $20 \%$ and $30 \%$, the distance from the gas turbine should not be higher than $22 \mathrm{~km}$ (variant E, which corresponds to the power of $226.9 \mathrm{MW}$ ) and $25 \mathrm{~km}$ (variant $\mathrm{H}-423.9 \mathrm{MW}$ ), respectively. In the case when the degree of storage is 0.2 , with $20 \%$ hydrogen in the gas mixture, even a 24 -hour gas turbine operation will not allow us to use all hydrogen production, if the road distance from gas turbine will be higher than $24 \mathrm{~km}$ (variant $\mathrm{G}$ 366.4 MW). 


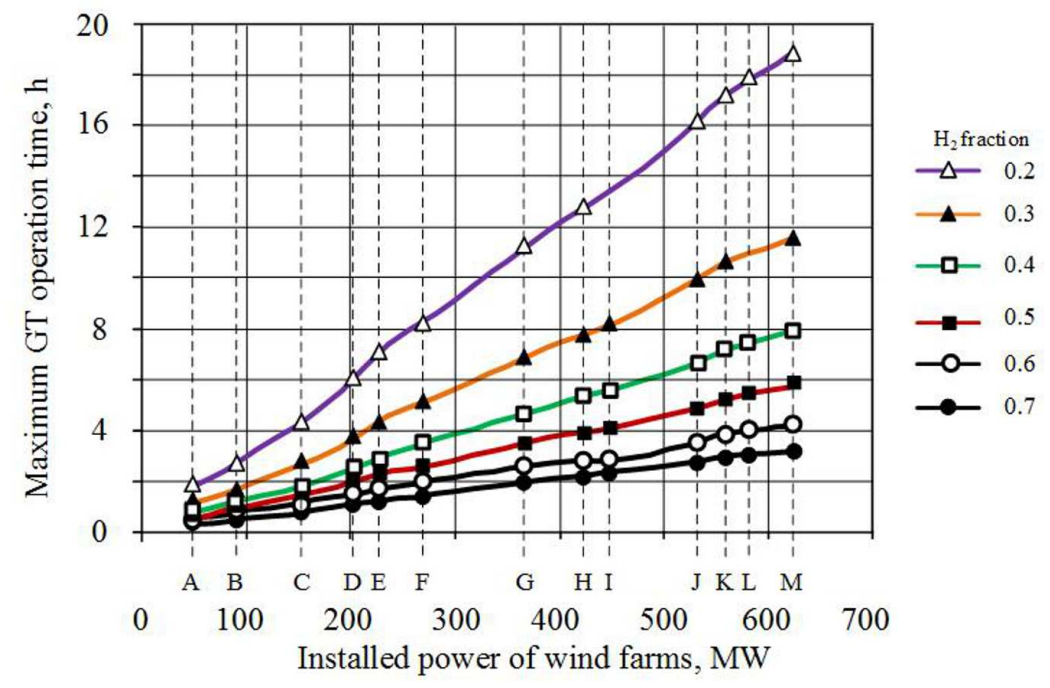

Figure 11: Influence of the amount of hydrogen in the mixture and the installed power of wind farms on the maximum daily operation time of the gas turbine for the degree of storage of 0.1 .

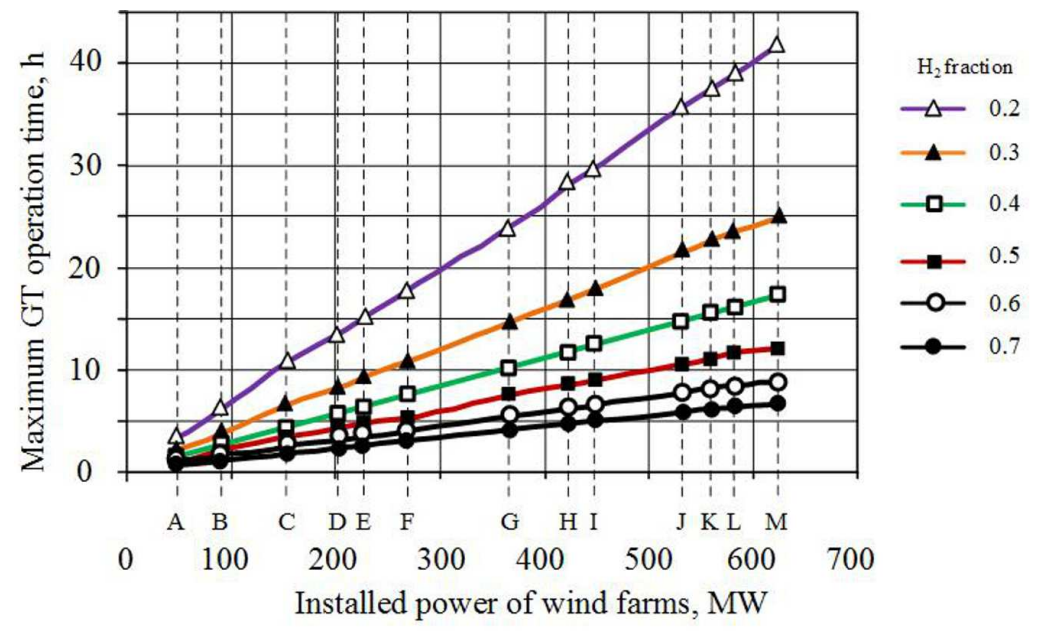

Figure 12: Influence of the amount of hydrogen in the mixture and the installed power of wind farms on the maximum daily operation time of the gas turbine for the degree of storage of 0.2 .

A similar situation will occur with hydrogen content at $30 \%$ and the distance higher than $37 \mathrm{~km}$ (variant L - 579.9 MW). It was considered that 
these cases may not take place and therefore no further analyses for these cases were carried out. With the operation time of eight hours, the distance limitation for hydrogen production will not occur at the hydrogen fraction of 0.7. For fractions of $0.6,0.5,0.4,0.3$, and 0.2, it will not be possible to utilize fully the stored hydrogen, if it is generated at a road distance from the gas turbine, higher than $35 \mathrm{~km}$ (variant $\mathrm{J}$ - installed power of wind farms $531.4 \mathrm{MW}$ ), $24 \mathrm{~km}$ (variant $\mathrm{G}-366.4 \mathrm{MW}$ ), $23 \mathrm{~km}$ (variant $\mathrm{F}-268.9 \mathrm{MW}$ ), $20 \mathrm{~km}$ (variant $\mathrm{C}-153.9 \mathrm{MW}$ ) and $19 \mathrm{~km}$ (variant B 90 MW) respectively.

The maximum turbine operation time is the one that will be required for the disposal of hydrogen which was stored during the maximum generation potential of hydrogen generators co-operating with wind farms. Due to the diverse potential of hydrogen production, the average daily operation time of the gas turbine in the year will be lower, as shown for the two different values of degree of storage in Figs. 13 and 14.

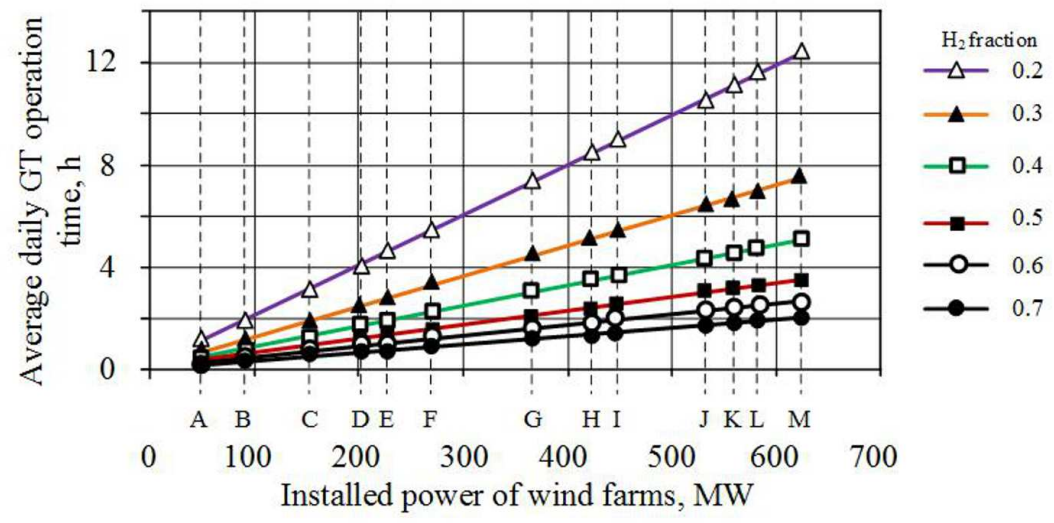

Figure 13: Influence of the amount of hydrogen in the mixture and the installed power of wind farms on the average daily operation time of the gas turbine for the degree of storage of 0.1 .

As shown in Figs. 13 and 14, with the lower power of the wind farms covered by the system, the average daily operation time of the gas turbine is often less than 1 hour. For the degree of 0.1, at road distances of up to $22 \mathrm{~km}$ (variant $\mathrm{E}-226.9 \mathrm{MW}$ ), regardless of the hydrogen content of the fuel mixture, the average daily working hours do not exceed in any case 5 hours. As shown in Fig. 9, the lower the operation time of the gas turbine, the lower the efficiency. In Figs. 15 and 16 respectively for the degrees of 


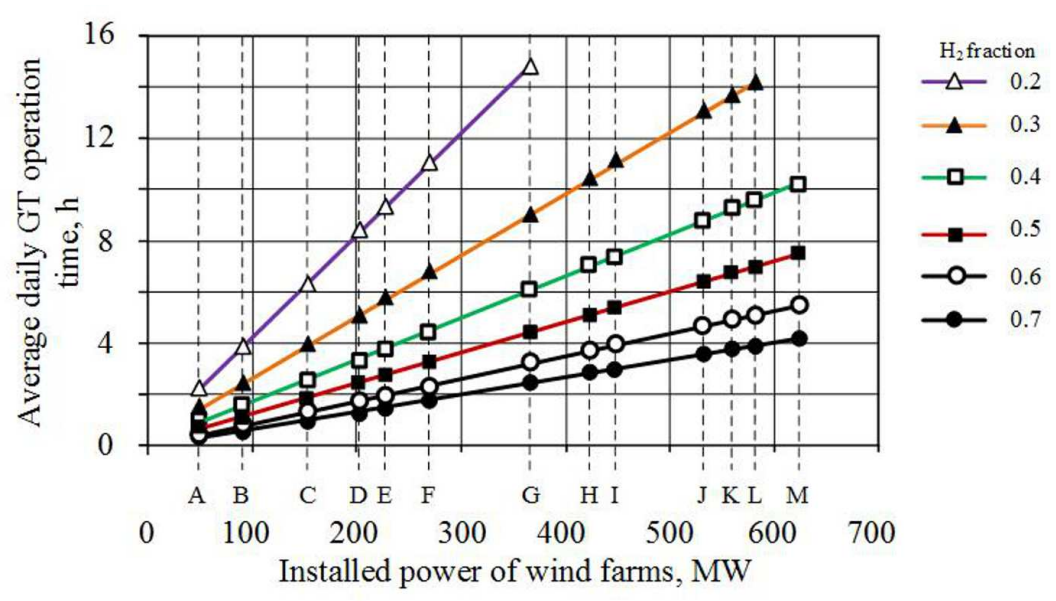

Figure 14: Influence of the amount of hydrogen in the mixture and the installed power of wind farms on the average daily operation time of the gas turbine for the degree of storage of 0.2 .

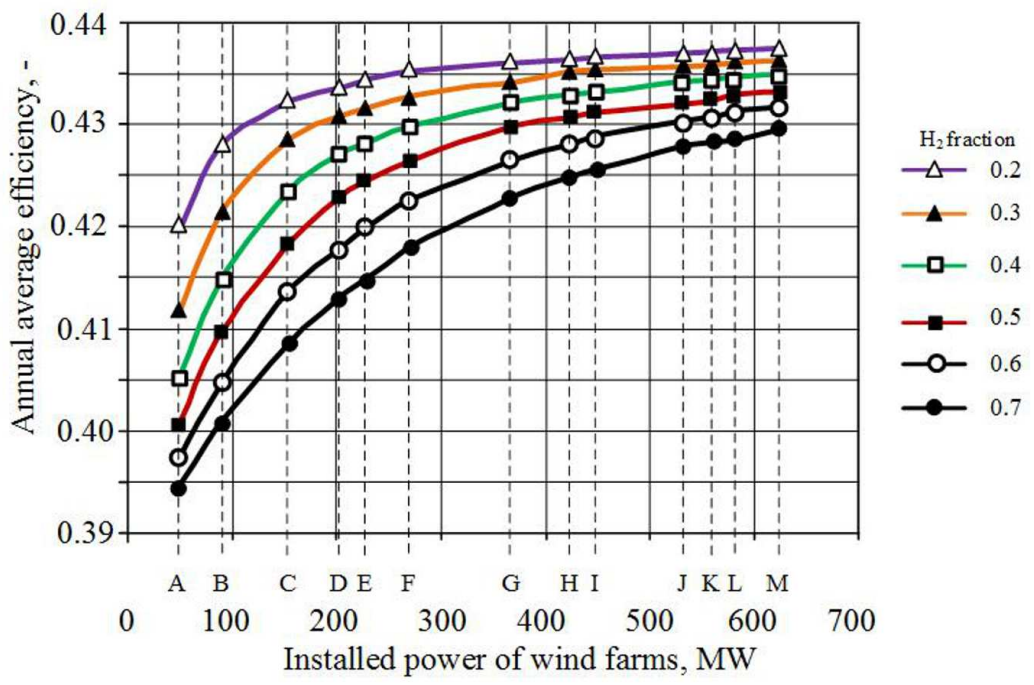

Figure 15: Influence of the amount of hydrogen in the mixture and the installed power of wind farms on the annual average efficiency of the gas turbine for the degree of storage of 0.1 .

storage of 0.1 and 0.2 for various wind farms power and different hydrogen content in the fuel mixture, the annual average efficiency of the gas turbine is presented. 


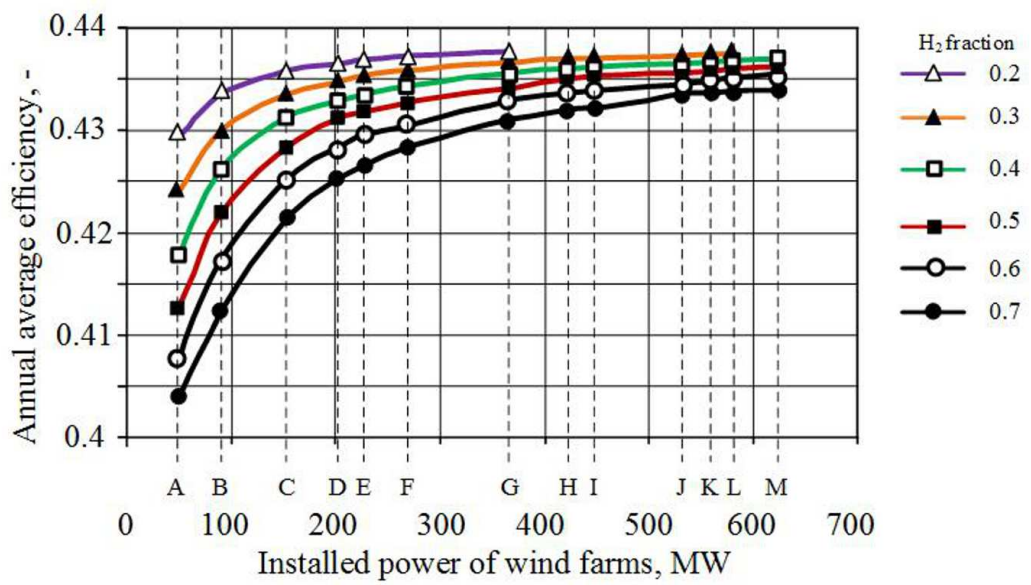

Figure 16: Influence of the amount of hydrogen in the mixture and the installed power of wind farms on the annual average efficiency of the gas turbine for the degree of storage of 0.2 .

\section{Economic analysis}

The P2G2P technologies may in the future be an important mechanism to compensate for the disparities between the demand for electricity and its production within wind and solar power plants. Currently, there is an increased interest in energy storage systems $[9,10]$. The development of such an important energy industry as energy storage, which may decide, in the reasonably near future about energy security conditions, may require the development of various types of support mechanisms. Such support will be less required, when the storage systems are more efficient and cheaper. The analysis presented in this chapter shows the current economic potential of the energy storage system in question.

As part of the economic analysis, the break-even sales price of electricity was calculated from the condition

$$
\mathrm{NPV}=0 .
$$

NPV is a net present value that for the investment and operating period (for $N$ years) is determined by the relation:

$$
\mathrm{NPV}=\sum_{\mathrm{t}=0}^{\mathrm{t}=\mathrm{N}} \frac{C F_{\mathrm{t}}}{(1+r)^{\mathrm{t}}},
$$


where: $C F_{\mathrm{t}}$ - cash flows for the year $t, r$ - the discount rate.

Cash flows $C F_{t}$ are determined by the general relationship $[2,11,12]$

$$
C F_{\mathrm{t}}=\left[-J+S-\left(K_{\mathrm{op}}+P_{\mathrm{d}}\right)+A+L\right]_{\mathrm{t}},
$$

where: $J$-total investment cost, $S$ - net revenue, $K_{\mathrm{op}}$ - operating costs, $P_{\mathrm{d}}$ - income tax, $A$-depreciation, $L$ - liquidation value. Therefore, the value of break-even sales price of electricity can be expressed as

$$
C_{\text {en.el. }}^{\mathrm{b}-\mathrm{e}}=\frac{\sum_{\mathrm{t}=0}^{\mathrm{t}=\mathrm{N}} \frac{J+K_{\mathrm{op}}+T-A-L}{(1+r)^{\mathrm{t}}}}{\sum_{\mathrm{t}=0}^{\mathrm{t}=\mathrm{N}} \frac{E_{\text {en.el }}}{(1+r)^{\mathrm{t}}}},
$$

where: $T$-taxes (the income and the property tax), $E_{\text {en.el }}-$ electricity production, $t$ - another year of analyses from $t=0$ (start of construction) to $t=N$ (last year of analyses).

The investment cost of an energy storage system consisting of a number of electrolysis installations, resulting from the amount of wind farms included in the system and the installation of the gas turbine was estimated on the basis of the dependence

$$
J=B\left(j_{\mathrm{GT}} N_{\mathrm{elGT}, \text { nom }}+j_{\mathrm{EI}} \sum N_{\mathrm{EI}}\right),
$$

where: $B-$ a coefficient taking account of the cost of construction (it was assumed $B=2), j_{G T}$ - unit purchase cost of gas turbine, $N_{\text {elGT,nom }}$ - nominal power of gas turbine, $j_{\mathrm{EI}}$ - unit purchase cost of electrolysis installation, $N_{\mathrm{EI}}$ - power of specific electrolysis installations. The unit purchase cost of gas turbine can be determined from a formula [2]

$$
j_{\mathrm{GT}}=21346\left(N_{\mathrm{elGT}, \mathrm{nom}}\right)^{-0.271} .
$$

The most important assumptions for the analysis are presented in Tab. 4 $[2,11-16]$. On the basis of the adopted assumptions, the break-even sale price of electricity in accordance with Eq. (6) was determined. Within the analysis, it was assumed that the electricity directed to the storage is free. The results of the analysis for the two values of the degree of storage $\gamma_{s}$ are shown in Figs. 17 and 18.

In analysing the results it can be noted that as the amount of hydrogen in the mixture increases, the break-even sales price of electricity increases. 
Table 4: Basic assumptions for economic analysis.

\begin{tabular}{|c|c|c|c|}
\hline \multicolumn{2}{|c|}{ Quantity } & \multirow{2}{*}{$\begin{array}{l}\text { Value } \\
20\end{array}$} & \multirow{2}{*}{$\begin{array}{c}\text { Unit } \\
\text { years }\end{array}$} \\
\hline Exploitation time & & & \\
\hline Construction time & & 2 & years \\
\hline Depreciation rate & & 6.67 & $\%$ \\
\hline Income tax rate & & 19 & $\%$ \\
\hline Discount rate, $r$ & & 4.86 & $\%$ \\
\hline $\begin{array}{l}\text { Unit cost of repair } \\
\text { (\% of the investment } \\
\text { cost) }\end{array}$ & \begin{tabular}{|l} 
Year 1 \\
$2-3$ \\
$4-7$ \\
$8-11$ \\
$12-15$ \\
$16-20$
\end{tabular} & $\begin{array}{l}1 \\
1.5 \\
2 \\
2.5 \\
3 \\
3.5\end{array}$ & $\%$ \\
\hline $\begin{array}{l}\text { Number of } \\
\text { employees }\end{array}$ & $\begin{array}{l}\text { Electrolysis } \\
\text { installation } \\
\text { GT installa- } \\
\text { tion }\end{array}$ & $\begin{array}{l}4 \\
0.2\end{array}$ & $\begin{array}{l}\text { Person/installation } \\
\text { Person/MW }\end{array}$ \\
\hline $\begin{array}{l}\text { Monthly salary in- } \\
\text { cluding related costs }\end{array}$ & & 1163 & EUR/per./month \\
\hline $\begin{array}{l}\text { Unit cost of trans- } \\
\text { port } \mathrm{H}_{2}\end{array}$ & & 1.67 & $\mathrm{EUR} / \mathrm{kg}$ \\
\hline $\begin{array}{l}\text { Unit price of } \mathrm{CO}_{2} \\
\text { emission }\end{array}$ & & 6 & $\mathrm{EUR} / \mathrm{Mg}$ \\
\hline $\begin{array}{l}\text { Unit price of natural } \\
\text { gas }\end{array}$ & & 7.75 & EUR/GJ \\
\hline $\begin{array}{l}\text { Unit price of dem- } \\
\text { ineralised water }\end{array}$ & & 70 & $\mathrm{EUR} / \mathrm{m}^{3}$ \\
\hline $\begin{array}{l}\text { Unit price of electrol- } \\
\text { ysis installation }\end{array}$ & & 1000 & $\mathrm{EUR} / \mathrm{kW}$ \\
\hline
\end{tabular}

Furthermore, it seems reasonable to consider larger storage systems with road distance from GT over $24 \mathrm{~km}(366 \mathrm{MW})$, that cooperate with electrolysis installations at the higher degrees of storage $\left(\gamma_{s}=0.2\right)$.

The lowest break-even sale price of electricity of $380 \mathrm{PLN} / \mathrm{MWh}$ was obtained for variant $\mathrm{G}$, where the transport distance was $24 \mathrm{~km}$, the installed power of the wind farms was $366.4 \mathrm{MW}$, the hydrogen fraction in mixture 0.2 and the degree of storage $\gamma_{s}=0.2$. For this case, the impact of the unit price of the electrolysis installation and the unit price of deminer- 


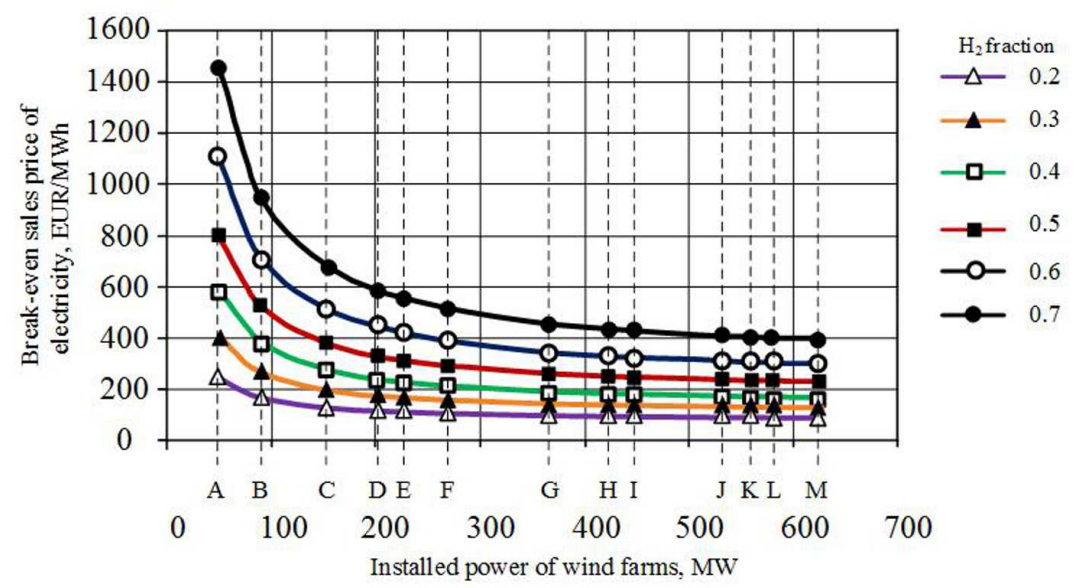

Figure 17: The break-even sale price of electricity depending on the amound of hydrogen in the mixture and the installed power of wind farms covered by the investment for the degree of storage of 0.1 .

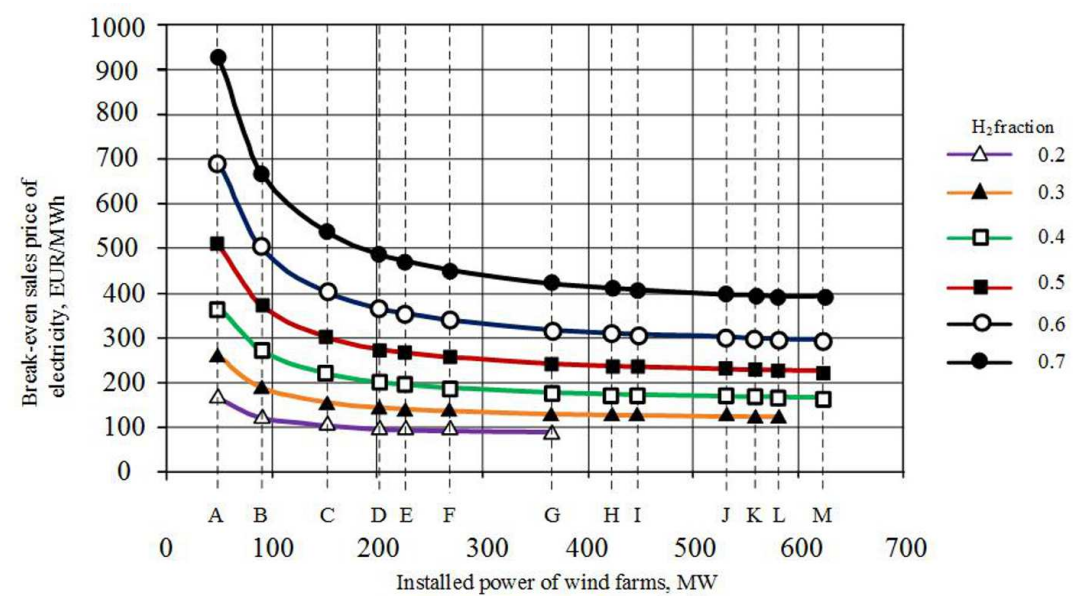

Figure 18: The break-even sale price of electricity depending on the amound of hydrogen in the mixture and the installed power of wind farms covered by the investment for the degree of storage of 0.2 .

alised water on the value of break-even price of electricity were analyzed. The results are shown in Figs. 19 and 20.

When analyzing the impact of unit costs of an electrolysis installation, it can be assumed that, with the development of electrolysis technology and hydrogen generators, and thus falling unit prices, the investments in 


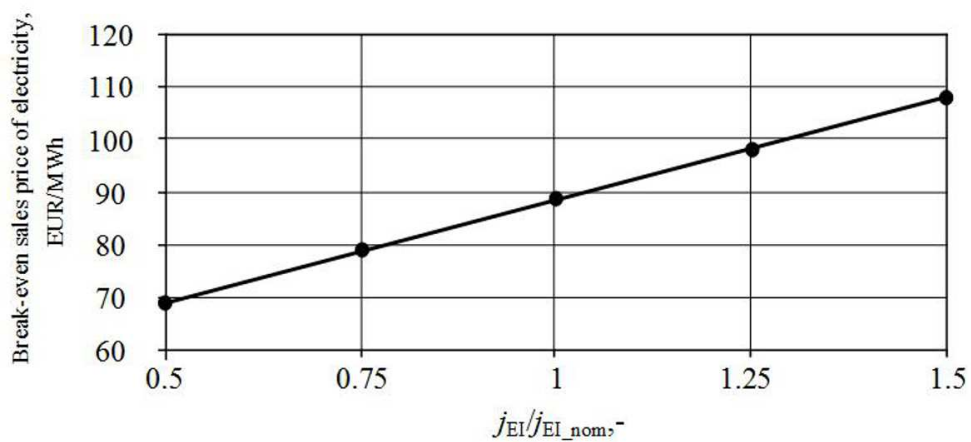

Figure 19: The break-even sale price of electricity for the most favourable case (variant $\mathrm{G}$, the degree of storage of 0.2 ), depending on the unit price of the electrolysis installation.

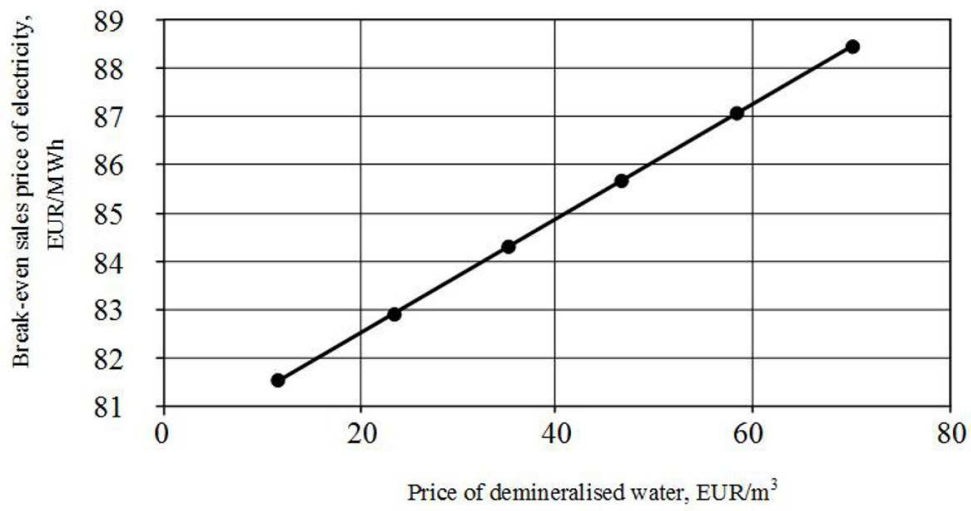

Figure 20: The break-even sale price of electricity for the most favourable case (variant $\mathrm{G}$, the degree of storage of 0.2 ), depending on the unit price of demineralised water.

such technologies may become more attractive to potential investors. In addition, the installation of individual water purification modules should be considered to reduce the operating costs of the electrolysis installation.

\section{Summary}

An analysis of the energy storage system using water electrolysis as a one of the processes was performed. The variant assumed the use of a gas turbine powered by a mixture of hydrogen and natural gas taken from the gas transmission grid. The analyses allowed us to determine the basic energy 
flows within the system and the selection of basic quantities, which can decide on the selection of machines and equipment. It was assumed that there is a gas turbine in the system with the characteristics of a turbine GE LMS100 available on the market. The calculations to demonstrate the effect of changing the fuel supplying the turbine on its operating characteristics were made using an own algorithm. The turbine calculations took into account the effects resulting from changes in energy and mass balances and did not consider the issue of kinetics of hydrogen combustion.

The analyzed case is the concept of large-scale energy storage, which is based on the use of wind farms with a total power of 623.9 MW. Such a large installation requires the use of very extensive infrastructure.

The analyzes were carried out for real location assumptions, determining regional potential for obtaining electricity for the hydrogen generation process. During the analyses, the road distance from the gas turbine site, thus the installed power of wind farms covered by the storage system was changed.

The results obtained indicated the significance of selection of the right value for the degree of storage $\gamma_{s}$. For specific gas turbine, this indicator decides about the daily time, in which the turbine is operated to ensure full utilization of the fuel. Economic analyses pointed to the advantage of systems with higher value of the degree of storage. No less important is the composition of the fuel mixture. The profitability analysis showed the advantage of lower hydrogen shares in the mixture with natural gas. It should be borne in mind that the possibility of construction of such a storage system depends on the functioning of the power system in the years to come, the interests of potential investors and companies responsible for the hydrogen infrastructure and on the development of support mechanisms for storage system.

Acknowledgements The research conducted within statutory research funds.

Received 2 October 2017

\section{References}

[1] www.ure.gov.pl (accessed 12.06.2017).

[2] Kotowicz J., Bartela Ł., Skorek-Osikowska A., Janusz-Szymańska K., Chmielniak T., Remiorz L., IluK T.: Thermodynamic and economic analysis 
of combined gas-steam cycle integrated with coal gasification and membrane separation of carbon diocide. Silesian University of technology Publishers, Gliwice 2012 (in Polish).

[3] http://www.imgw.pl (accessed [1.07.2017]).

[4] Kotowicz J., Bartela Ł., Węcel D., Dubiel K.: Hydrogen generator characteristics for storage of renewably-generated. Energy 118(2017), 156-171.

[5] GE Energy. LMS100: Flexible Power.

[6] GE Energy. New High Efficiency Simple Cycle Gas Turbine - GE's LMS100 ${ }^{T M}$.

[7] Chmielniak T., Rusin A., Czwiertnia K,: Gas Turbines. Ossolineum, Wrocław 2001.

[8] Tabari A., Khaledi H., Benisi A.H.: Comperative evaluation of advanced gas turbine cycles with modified blade cooling models. In: Proc. GT2006, ASME turbo Expo 2006: Power for Land, Sea and Air, May 8-11, 2006, Barcelona.

[9] Bussar C, Stocker P, CAi Z, et al.: Large-scale integration of renewable energies and impact on storage demand in a European renewable power system of 2050 sensitivity study. J. Energy Storage 6(2016), 1-10.

[10] Milewski J, Szczęśniak A, Lewandowski J.: Dynamic characteristics of auxiliary equipment of SOFC/SOEC hydrogen peak power plant. IERI Procedia 9(2014), 82-87.

[11] Kotowicz J., Bartela Ł.: The influence of economic parameters on the optimal values of the design variables of a combined cycle plant. Energy 35(2010), 911-919.

[12] Kotowicz J, BARTela E.: The influence of the legal and economical environment and the profile of activities on the optimal design features of a natural-gas-fired combined heat and power plant. Energy 36(2011), 1, 328-338.

[13] Singh, S., Jain, S., Ps, V., Tiwari, A.K., Nouni, M.R., Pandey, J.K., et al.: Hydrogen: A Sustainable Fuel for Future of the Transport Sector. Renew. Sust. Energ. Rev. 51(2015), 623-633.

[14] Bartela Ł., Kotowicz J., Dubiel K.: Technical - economic comparative analysis of the energy storage systems equipped with the hydrogen generation installation. J. Power Technologies 96 (2016), 2, 92-100.

[15] http://vertis.com (accessed 18.09.2017).

[16] Weinert J.X., Shaojun L., OGden J.M., Jianxin M.: Hydrogen refueling station costs in Shanghai. Int. J. Hydrogen Energ.32(2007), 4089-4100. 